ArTigos

\title{
O CUIDADO DE SI NA PRÁTICA EDUCATIVA: A RESISTÊNCIA NA SOCIEDADE DA VISIBILIDADE
}

\author{
Kátia Menezes de SousA*
}

\begin{abstract}
Resumo
O presente artigo discute a resistência produtiva para a Educação frente ao poder disperso exercido na sociedade contemporânea em suas práticas de controle e de busca por visibilidade. Para relacionar a educação ao tipo de relaçóes de poder e resistência do presente, faz-se necessário o questionamento acerca da construçáo da ética: ela é resultado de práticas possibilitadas por exercícios do cuidado de si, da renúncia a si mesmo ou do conhecer-se? Assim, minha expectativa é poder situar as práticas escolares, que colocam a Educação a serviço dessa sociedade do espetáculo, e as relaçóes de poder/resistência possibilitadas/ impedidas pelos modos de subjetivação na produção do saber. Parto da questão: o que nós, professores, estamos fazendo de nós mesmos? Busco uma possível resposta no entendimento do que seja uma estética da existência.
\end{abstract}

PalaVras-Chave: educação, discurso, poder, ética.

The care of the Self in the educative practice: the resistance in the society of visibility

\section{Abstract}

The present article discusses the productive resistance to the Education in the face of the power dispersal that is exerted in the contemporary society in its practices of control and visibility. In order to connect the education with the type of power relations and resistance in the present, it is necessary to put the question about the ethics construction: it is a result of practices made possible by the exercises of the care of the self, of the renunciation of the self or of the self-knowledge? Then, my expectation is that I may point the school practices, that place the education as in a service of the spectacular society, and power/resistance relations that are made possible/blocked by the ways of subjectivation in the knowledge production. I start from the question: what are we, teachers, doing with ourselves? I search for a possible answer in the understanding of what has been an aesthetics of the existence. KEY WORDS: education, discourse, power, ethics.

Professora de Análise do Discurso e Estágio de Português da Faculdade de Letras da Universidade Federal de Goiás. Doutora em Estudos Linguísticos pela UNESP. E-mail: km_souza@yahoo.com.br. 
Pretendo, por meio deste texto, analisar o tipo de sociedade que se constitui na atualidade para propor que o cuidado de si, nos termos de Michel Foucault, pode ser a forma de resistência capaz de produzir efeito no interior do poder exercido em nossa sociedade e nas práticas educativas. Para isso, busco apoio nas reflexóes de Foucault, e de seus comentadores, acerca das questóes que dizem respeito aos tipos de sociedades já constituídas, às relaçóes de poder-saber e à ética como estética da existência e como cuidado de si.

Usando a expressão de Veiga-Neto (2003), a relação do ser-consigo, e a reflexão de Gallo (2006) acerca das implicações éticas para a educação, pretendo, ainda, refletir, com base nos escritos de Foucault, sobre o que nós, educadores, estamos fazendo de nós mesmos.

A opção por Foucault se justifica por este privilegiar o nível do discurso, articulando o saber, o poder e o ser. Assim, situando-me no lugar de analista do discurso, tomo as práticas educacionais como discursividades que, como explica Dosse (2007) ao realizar a história do pensamento foucaultiano, pertencem ao campo do saber, pois o saber lhes é consubstancial. Como discursos, as práticas educacionais, da mesma forma que objetivam os sujeitos envolvidos na situação escolar, também funcionam como técnicas de subjetivação dos indivíduos com os saberes de que se apropriam em detrimento de outros que teimam em aparecer em sua interdição.

Assim, questiono os discursos educacionais da atualidade, procurando situar as diferentes construções de sujeito conforme a irrupção dos saberes que constituem e se desenvolvem a partir da lei, da religião, da ciência e da mídia. Esses saberes, conforme Foucault (2004a), em "O cuidado com a verdade", utilizam técnicas que impóem práticas discursivas e náo-discursivas de subjetivação, configurando diferentes tipos de sociedade que, por suas práticas, instauram o que Foucault denominou de sociedades de soberania, de disciplina, de controle e, juntamente com outros pensadores, acrescento, diante do inquestionável papel da mídia nas diferentes instâncias do saber, uma sociedade do espetáculo. Essas sociedades impóem diferentes formas de interpretar, olhar o mundo e construir os acontecimentos sobre os quais vão falar.

Segundo a análise de Fonseca (2003), o pensamento de Foucault o leva para além dos limites estabelecidos por uma separação arbitrária do saber e se abre para as preocupaçóes que julga úteis para pensar o presente. Penso que posso justificar, a partir disso, a escolha de Foucault para analisar a rela- 
ção entre o discurso escolar e a constituição do sujeito, pois já não é de hoje que ouvimos as reclamaçóes sobre o comportamento das crianças e jovens e sobre o fracasso da escola na constituição dos sujeitos aluno e professor.

Em toda sua trajetória teórica, o sujeito é a preocupação principal de Foucault, conforme ele mesmo admite em "O sujeito e o poder" (1995, p. 232): "não é o poder, mas o sujeito, que constitui o tema geral de minha pesquisa". Porém, não é do sujeito em si que Foucault vai tratar, mas da problemática de sua constituição "que se dá no presente e que fabrica, para o presente, um tipo específico de indivíduo" (Fonseca, 2003, p. 10). É essa preocupação, mesmo que velada ou disfarçada por uma investigação histórica das práticas, que perpassa a obra de Foucault. Ele questiona a existência de um sujeito unificante, transcendental, psicológico e aponta para um sujeito disperso, constituído, deslocado da idéia de centralidade e de ser um dado preexistente.

Por esse deslocamento, Foucault foi, por várias vezes, acusado de não reconhecer a existência do sujeito, contudo, pode-se perceber um equívoco nessa acusação, pois o que ele mostrou, com seus estudos, é que não existe uma subjetividade soberana, mas diferentes formas de subjetividade. Trabalhando com a relação saber/poder/sujeito/verdade, Foucault (1995) demonstra que o saber situa e adota, como dependente, o sujeito, e questiona as relaçóes do saber com o poder, procurando conhecer a maneira pela qual o saber circula e funciona. $\mathrm{O}$ poder náo estaria tanto em uma ou em outra instituiçáo, grupo ou classe, mas em uma técnica, em uma forma de poder.

Esta forma de poder aplica-se à vida cotidiana imediata que categoriza o indivíduo, marca-o com sua própria individualidade, liga-o à sua própria identidade, impóe-lhe uma lei de verdade, que devemos reconhecer e que os outros têm que reconhecer nele. É uma forma de poder que faz dos indivíduos sujeitos. Há dois significados para a palavra sujeito: sujeito a alguém pelo controle e dependência, e preso à sua própria identidade por uma consciência ou autoconhecimento. (Foucault, 1995, p. 235)

$\mathrm{Na}$ escola, quando objetivados, mensurados, numerados, comparados, tanto professores quanto alunos sofrem um controle por meio do discurso, dos comentários sobre os acontecimentos que desmoralizam a instituição escolar e o convívio social, e podem se prender à nova identidade por sua própria consciência, por práticas de subjetivação, para se reco- 
nhecerem como sujeitos de um fracasso, de uma incompetência, de uma incapacidade de responder aos saberes que lhes chegam como verdades.

Percebe-se, assim, que o sujeito não existe enquanto essência perene, pronto e já dado, e que o problema deve ser colocado em torno da constituição desse sujeito. O objetivo de Foucault era produzir uma história dos diferentes modos de subjetivaçáo do ser humano dentro da nossa cultura. Ele mostra que a busca por um estatuto de ciência fez com que os saberes fossem considerados como resultados de investigaçóes que objetivaram o homem como falante, produtivo e vivente, dividindo-o, por exemplo, em louco e são, bandido e cidadão de bem, pecador e imaculado, competente e incompetente etc. Além dessas práticas de objetivação, há também as formas de subjetivação, pelas quais o ser humano é transformado em sujeito; ele deve ser capaz de se reconhecer como sujeito de alguma coisa.

Michel Foucault, ao fazer suas pesquisas sobre os temas sujeito, poder e saber, investiga-os a partir de práticas discursivas e não-discursivas que constituíram as sociedades soberanas e depois as disciplinares. Quanto às primeiras, Foucault (2006) esclarece que o poder de soberania é uma relaçâo de poder que vincula soberano e súdito por meio de uma anterioridade fundadora, de um direito divino, de uma conquista, uma vitória, um ato de submissáo, um ato entre o soberano que concede ajuda, privilégios, proteção, e o súdito que, em compensação, se empenha. Quanto às sociedades disciplinares, Foucault (2006) mostra que elas começam a surgir em fins do século XVII, caracterizando-se por implicar, não uma coleta do produto ou de parte do tempo, mas uma apropriação total do corpo, dos gestos, do tempo, do comportamento do indivíduo. O poder disciplinar fabrica corpos sujeitados, vincula a função-sujeito ao corpo; o indivíduo não é aquilo a que se prende o poder político, mas é efeito produzido pelas técnicas da vigilância e do controle.

Discutindo a constituição do indivíduo moderno, a partir dos mecanismos disciplinares, Foucault (1987) demonstra que há práticas em nossa cultura que fizeram do homem um objeto dócil e útil, e, em uma entrevista intitulada "O retorno da moral", Foucault (2004b) defende a idéia de que há formas de subjetivação que fazem do homem um sujeito, que o constituem como um sujeito preso a uma identidade que lhe é atribuída como própria. Assim, o indivíduo moderno se constituiria em um objeto dócil e útil, e o sujeito seria o resultado da constituição do indivíduo perante os mecanismos de subjetivaçáo presentes na atualidade. 
De acordo com Dosse (2007), Foucault acompanha as condições da autodisciplina do sujeito na multiplicação e extensão dos poderes de normalização que afetam o indivíduo em todos os espaços do sistema social. Observa a passagem de uma sociedade jurídico-discursiva, em que a regra, a lei, é enunciada pelo poder que funciona de maneira uniforme para uma sociedade fundamentada na disciplina e em normas disciplinares. Com a crise da soberania real, o direito de punir torna-se outro; deixa de ser o meio de reativar a figura do príncipe para converter-se no meio de defesa da sociedade. Conforme Foucault (1987), com a multiplicação das prisôes, dos colégios e das casernas, ocorre o estabelecimento de um sistema disciplinar. Assim, "a modernidade traz consigo o controle das populaçôes a partir de instituiçóes específicas, concebidas para serem mais eficazes" e "todo o sistema social se modifica a um novo esquema de visibilidade" (Dosse, 2007, p. 311). Na sociedade de soberania, o poder era exercido no próprio corpo do soberano, na sociedade disciplinar, a visibilidade tem de permitir o conhecimento dos fatos e gestos de toda uma populaçáo, e o poder se torna anônimo. De acordo com Fonseca (2003), para a época da disciplina, todo indivíduo é singularizado e possui uma identidade que traz a marca da utilidade e da docilidade.

Deleuze (1992), em suas análises, constata que existem, no final do século $\mathrm{XX}$, sociedades de controle ou de comunicação, que já não são exatamente disciplinares. Ele afirma que o próprio Foucault foi um dos primeiros a dizer que as sociedades disciplinares estavam ficando para trás. Nas sociedades de controle, a comunicação é instantânea e o controle é contínuo; a empresa substituiu a fábrica; a formação permanente tende a substituir a escola. A empresa introduz uma rivalidade como motivação que contrapóe os indivíduos entre si e atravessa cada um, dividindo-o em si mesmo. Deleuze (1992) ainda demonstra que, nas escolas, passam a vigorar as formas de controle contínuo, avaliação contínua, e a ação permanente sobre a escola (destacam-se os sistemas nacionais de avaliação dos alunos e das instituiçóes), o abandono das pesquisas na Universidade e a introdução da empresa em todos os níveis de escolaridade. $\mathrm{O}$ aluno deixa de ser operário e passa a ser cliente.

O caráter empresarial constitutivo da escola na atualidade pode ser percebido, principalmente, em propagandas veiculadas pelos dispositivos midiáticos que vendem produtos para que a empresa escola possa atuar no mercado de forma mais atrativa e rentável. Assim, em uma propaganda de uma feira internacional de educação, constatam-se enunciados do tipo: 
[1]

1- Para os gestores, a FEIRA [o termo FEIRA foi utilizado em lugar de seu nome] é a oportunidade de conhecer toda a tecnologia disponível para auxiliar a administração das suas escolas. Para os professores, um mundo de informaçóes, de contatos e desenvolvimento pessoal e profissional; 2- Mais de 250 empresas expositoras; 3- Produtos e serviços para escolas e universidades; 4- Novidades e lançamentos da indústria da educação.

Neste exemplo, fica registrada a relação entre empresas e entre indústria e empresas. $\mathrm{O}$ anúncio publicitário visa a um determinado interlocutor, o consumidor proprietário de escolas, como pode ser percebido na expressão "suas escolas". Os produtos oferecidos se voltam para a melhoria da qualidade administrativa e profissional das escolas, como se a tecnologia pudesse garantir tanto a boa administração quanto a adequada formação dos professores. Estes, na "indústria da educação", são tratados como produtos no pacote que compóe a escola, sendo necessário também que passem por modernizaçóes. A empresa do anúncio oferece produtos a seus clientes, donos de escolas, para que estes possam oferecer um bom serviço a seus clientes, os alunos. A propaganda é divulgada democraticamente para as escolas, mas, ao mesmo tempo, acaba impondo uma competição, pois lucra mais quem atrai mais consumidores. Assim, pode-se falar de um controle permanente que inculca a necessidade constante da modernização e da exposição das vantagens, dos resultados, e da oferta de produtos. A escola disciplinar convive com a escola que controla a vida de seus alunos e a prática de seus professores com o auxílio das novas tecnologias.

A obra de Foucault, conforme Hardt e Negri (2004), permite reconhecer uma transição histórica, de época, nas formas sociais da sociedade disciplinar para a sociedade de controle. A sociedade disciplinar seria aquela na qual o comando social é construído mediante uma rede dispersa de dispositivos que produzem e regulam os costumes, os hábitos e as práticas produtivas. Por meio de instituiçóes disciplinares (prisão, fábrica, hospital, escola, universidade), que fornecem explicaçóes lógicas para a razão da disciplina, essa sociedade póe para funcionar mecanismos de inclusão e de exclusão. A sociedade de controle desenvolve mecanismos cada vez mais democráticos, distribuídos por corpos (em sistemas de bem-estar, atividades monitoradas) e cérebros (em sistemas de comunicação, redes de informação) dos cidadáos. Essa sociedade pode ser caracterizada por uma intensificação e uma síntese dos aparelhos de normalização de disciplina- 
ridade. Exemplo disso é a ditadura do bem-estar, da beleza, do prazer; é a obrigatoriedade de ser feliz segundo padróes já testados e definidos. A escola, dentro desse modelo, implanta formas de controle que passam pelo prazer da leitura, pela modernização tecnológica, pela vigilância dos comportamentos das famílias de seus alunos, pelas festas comemorativas, pelas dinâmicas de descontração, pelas campanhas de vacinação, pela prevençáo de doenças e de problemas odontológicos etc.

Segundo Machado (2003), o indivíduo é uma produção do saber e do poder; o poder disciplinar não destrói o indivíduo, mas o fabrica; e o saber náo é neutro, pois todo conhecimento, seja ele científico ou ideológico, só pode existir a partir de condições políticas que são as condições para que se formem tanto o sujeito quanto os domínios de saber. Assim, o sujeito é produto e efeito, antes de ser origem e fonte. Foucault (1996), em $A$ verdade e as formas jurídicas, mostra que as práticas sociais do controle e da vigilância podem engendrar domínios de saber, fazendo aparecer novos objetos, novos conceitos, novas técnicas e fazendo nascer formas novas de sujeitos e de sujeitos de conhecimento.

Acompanhando essa modernização dos mecanismos disciplinares, Foucault (2001), em "A vontade de saber", analisa que a hipótese da repressão atribuída ao poder disciplinar cedeu lugar para o biopoder. Seguindo a concepção da hipótese repressiva, há a idéia, segundo Rabinow e Dreyfus (1995), de que a resistência à repressáo seria uma batalha importante, a voz transgressora desafiaria o poder repressivo, pois a oportunidade "de falar contra os poderes, dizer a verdade e prometer prazer; ligar entre si a iluminação, a libertação e volúpias múltiplas; manter um discurso onde se juntam o ardor do saber, a vontade de mudar a lei e o jardim esperado de delícias" (Foucault, 2001, p. 13) seria a forma de restabelecer a verdade distorcida pelo poder.

$\mathrm{Na}$ passagem da sociedade disciplinar para a sociedade de controle, um novo paradigma de poder é realizado, o qual é definido, pela leitura que Hardt e Negri (2004) fazem da noção de Foucault, pelas tecnologias que reconhecem a sociedade como reino do biopoder. Com essa forma de poder, todo o corpo social fica abarcado pela máquina do poder que funciona como um controle que se estende pelas profundezas da consciência e dos corpos da população. Conforme Foucault (2001), seria necessário falar de biopoder para designar aquilo que faz entrar a vida e seus mecanismos no domínio dos cálculos explícitos e faz do poder-saber um agente de transformação da vida humana. Assim, há uma preocupação com o bem-estar 


\section{Revista Solta a Voz, v. 19, n. 1}

em termos de necessidade e felicidade das pessoas e com novas técnicas para maximizar a vida. $\mathrm{O}$ biopoder acabou incorporando a hipótese repressiva.

Analisando os dispositivos midiáticos, Hardt e Negri (2004) explicam que a comunicação de massa expressa o movimento de globalização e controla o sentido de direção do imaginário que percorre essas conexóes comunicativas, ou seja, o imaginário é guiado e canalizado dentro da máquina de comunicaçáo. $\mathrm{O}$ poder, enquanto produz, organiza; enquanto organiza, fala e se expressa como autoridade. A linguagem, à medida que comunica, produz mercadorias, mas, além disso, cria subjetividades, póe umas em relação às outras, e ordena-as.

Com essas transformaçóes das práticas, os dizeres também materializam e garantem as práticas e fazem funcionar outras práticas advindas das transformaçóes. Os enunciados falam pela e sobre a escola e, mais que isso, constituem as identidades do aluno incluído, normal, disciplinado e do aluno excluído, anormal, desviado dos padróes; do professor produtor, repassador, facilitador, mediador do conhecimento. Assim, torna-se relevante descrever e analisar esses enunciados, levando-se em conta o lugar em que foram realizados, o momento de sua enunciação, a posição ocupada pelos enunciadores e interlocutores e a relação que estabelecem com outros que já vieram e com os que ainda podem vir.

Exemplos das práticas do biopoder referentes à instituição escolar são numerosos em nossa sociedade atual, mas cito alguns, reproduzindo, aqui, enunciados que circularam na Folha de S. Paulo recentemente, a partir dos resultados do Exame Nacional de Ensino Médio (ENEM):

[2]

\section{Campeã do Enem impóe rigor a docente}

Melhor colégio estadual da capital paulista no exame a estudantes já mandou para psiquiatra professores que faltaram muito.

Diretora do Rui Bloem afirma que faltam recursos para a unidade; apesar de liderar entre estaduais, foi a $335^{\text {a }}$ na lista geral da cidade.

[3]

\section{Pior particular supera $75 \%$ das estaduais}

$\mathrm{Na}$ cidade de SP, de 572 escolas estaduais, apenas 157 ficaram acima da média de 50,8, obtida pelo Colégio Integral Inaci.

A melhor escola estadual foi a Rui Bloem, no bairro da Saúde, que obteve média 59,3 e ficou em $335^{\circ}$ no ranking geral da cidade. 
[4]

\section{$1^{\circ}$ do país tem período integral e é só para meninos}

Colégio de São Bento diz valorizar cultura clássica e formação humanística.

Coordenadora afirma que bom corpo pedagógico e alunos com perfil socioeconômico elevado explicam o resultado.

As manchetes apresentam constatações "comprovadas" que dizem "a verdade" sobre as escolas brasileiras de Ensino Médio, definindo o que são escolas públicas e escolas particulares. Os números, as estatísticas, os dados comprovados com critérios de pesquisa científica constituem os dispositivos de controle dessa forma de poder que regula a vida da população, oferecendo alternativas para que essa população seja bem sucedida dentro de padróes que a própria sociedade do biopoder impóe. Assim, podem-se ler dados que objetivam a escola particular como a que prepara melhor o aluno, a escola pública como a incapaz de formar bons estudantes. A partir desses dados, outro dispositivo do biopoder entra em ação com as receitas generalizantes de como conseguir bons resultados. Os discursos de auto-ajuda são recuperados nas fórmulas que sugerem o modo como obter sucesso no ensino: é preciso rigor com professores, os faltosos têm problemas psiquiátricos; é preciso separar meninos e meninas, os meninos são melhores que as meninas; é preciso valorizar a cultura clássica e a formação humanística; os alunos com melhor perfil socioeconômico são melhores.

Tais fórmulas objetivam a idéia da escola ideal e acabam funcionando como técnicas de subjetivação que fazem com que os indivíduos se identifiquem com certos lugares e categorias. As identidades estão aí se constituindo e verdades sendo lançadas: professores são faltosos, propensos a problemas psiquiátricos, as meninas são menos capazes, os pobres não conseguem aprender etc. Com mecanismos que garantem a visibilidade das instituições, tem-se garantido o controle sobre seus integrantes, assistese a um acirramento da competição entre as várias esferas da sociedade e faz-se das diferenças o espetáculo onde todos entram em cena.

Dessa forma, percebe-se que os discursos produzem mercadorias, imprescindíveis na vida das pessoas, e que, ao mesmo tempo, criam subjetividades, para encontrar, alinhavadas a esses discursos, formas de resistência que possam permitir aos sujeitos uma reflexão sobre os acontecimentos e um domínio maior sobre suas escolhas. 


\section{Revista Solta a Voz, v. 19, n. 1}

As estratégias de poder e de resistência afetam as formas de exercício do poder da vida cotidiana e classificam os indivíduos em categorias. A ciência e seus divulgadores midiáticos, com suas técnicas atuais de objetivação e de subjetivação, agrupam os indivíduos e, ao mesmo tempo, os individualizam, como pode ser percebido nas matérias impressas e televisivas e nas propagandas que divulgam a moda, constroem os desejos, definem o que é ser criança, jovem, mulher, homem, idoso, aluno, professor, homossexual, saudável, doente, grupo de risco, condenado a doenças etc. Para exercer o seu poder sobre os discursos que circulam e sobre os comportamentos e escolhas, a mídia, juntamente com as novas tecnologias, não age sozinha, mas elege certos saberes já consagrados como verdades.

Nesse sentido, cabe ressaltar a idéia difundida de que a educação é sempre o lugar privilegiado para as mudanças e que o professor é o sujeito privilegiado, do ponto de vista das políticas curriculares, como o articulador de mudanças. Assim, na escola empresa, vive-se a ditadura da mudança, sem a reflexão de que as mudanças são construídas, fazendo com que o professor as aceite de forma a corroborar poderes expressos pelos agentes de mudanças, gestores e planejadores de currículo. De acordo com Martins (2004), é estranha a relação entre história e mudança; é perversa a lógica de que os homens devem preparar-se para as mudanças e se acercar delas com as ferramentas necessárias para a adaptação ao novo que não cessa de chegar; são contraditórias as pesquisas assentadas em paradigmas sobre a originalidade do conhecimento escolar, mas representantes de posturas autoritárias dos pesquisadores. A autora esclarece que essas questóes são relativas ao poder, ao entendimento e à consciência de que o poder está em todos os lugares e constitui-se numa forma pela qual as açóes particulares modificam outras açóes ou guiam a conduta de cada um.

Inserido em relaçóes de poder e resistência, o professor, ora reduzido a um técnico, ora promovido a agente essencial de transformação social, é objetivado nas tentativas de "definir o que é, o que deve ser e como deve ser o professor" (Martins, 2004, p. 109). Chega-se à fórmula do professor crítico, da autonomia no exercício de ensinar, duas palavras banalizadas pela força do uso que, ao mesmo tempo em que as esvazia de sentido, constrói a idéia da obviedade e oferece a ilusão de uma liberdade de escolha. $\mathrm{O}$ posicionamento crítico exige trabalho, exercício daquele que quer conhecer e ensinar. A autonomia requer responsabilidade, assunção de escolhas e de 
decisões, luta pelo que se escolhe, mesmo sabendo que se deverá abrir mão de algo em favor da escolha.

Retirar os termos crítica e autonomia da obviedade e do senso comum exige que o olhar se volte de outra forma para o conhecimento. Foucault (1996), tomando como ponto de partida as idéias de Nietzsche, afirma que o conhecimento foi inventado, que ele não está inscrito na natureza humana; ele é resultado do jogo, do afrontamento, da junção, da luta, do combate; é violação das coisas a conhecer e não percepção, reconhecimento, identificação delas ou com elas. Pode ser por isso que a identidade da escola se mantém obscura para aqueles que a tomam como objeto de pesquisa, pois, conforme Martins (2004), estes procuram encontrar nela uma intrínseca e irrevogável simetria entre os objetivos que lhe foram atribuídos pelos agentes planejadores e a prática curricular. Nessa avaliação, o autor (idem) coloca uma pergunta: os planejadores e gestores querem deixar de controlar o professor e este quer, de fato, pagar o preço por essa autonomia?

O medo da autonomia e a ilusão da liberdade e da necessidade do controle constituem o pano de fundo do cenário escolar atual. É por meio dessa liberdade aparente que os indivíduos da escola se subjetivam e se constituem como sujeitos. Segundo Deleuze (2005, p. 110), em Foucault,

a subjetivação do homem livre se transforma em sujeição: por um lado, é a submissão ao outro pelo controle e pela dependência, com todos os procedimentos de individualização e de modulação que o poder instaura, atingindo a vida cotidiana e a interioridade daqueles que ele chamara seus sujeitos; por outro lado, é o apego (de cada um) à sua própria identidade mediante a consciência e o conhecimento de si, com todas as técnicas das ciências morais e das ciências do homem que vão formar um saber do sujeito.

A subjetivação é um trabalho do próprio indivíduo conforme as técnicas (da disciplina, do controle, do espetáculo) a que é submetido. Atualmente, ele é disciplinado para se portar com altivez, ter uma vida saudável, feliz; é controlado em sua produção, seus gastos, emoções, vícios, em sua alimentação; é espetacularizado para ser competitivo, mostrar e provar o que faz, oferecer suas qualidades, se tornar visível. As relaçóes de poder criam mecanismos que visam a constituir os objetos sobre os quais incidem. São relações que incitam, suscitam, incentivam e fazem falar. Trata-se 


\section{Revista Solta a Voz, v. 19, n. 1}

de um poder exercido de forma sutil, sem repressão explícita, e, por isso, necessita formar, organizar e colocar em circulação certos saberes.

Às pessoas que têm negado o seu direito de reivindicar uma identidade distinta da classificação atribuída e imposta, conforme se pode ler em Bauman (2005), é imputada a condição de subclasse. Aqui, encontram-se aqueles que fugiram da escola, as mães solteiras, os homossexuais, os viciados em drogas, os mendigos, que são excluídos do espaço social (também da escola) onde as identidades são buscadas, escolhidas, construídas, avaliadas, confirmadas ou refutadas. $\mathrm{O}$ mesmo autor aponta também que as relaçóes interpessoais são lugares de hesitação, ambigüidade e ansiedade, objetos de desejo, mas também de medo. Assim, se, nas sociedades anteriores, as pessoas eram moldadas e treinadas como produtoras, hoje, as pessoas são moldadas e treinadas como consumidoras e o resto vem depois. Consomem, sobretudo, discursos; discursos sobre comportamentos, tipos de relacionamentos, alimentaçáo, educaçáo dos filhos, enriquecimento etc.

Sant'Anna (2005), apoiada em Deleuze, demonstra que o marketing é o instrumento de controle social da época atual, fazendo com que uma espécie de totalitarismo fotogênico se relacione com um esvaziamento da política e uma inflação da publicidade: "a política é percebida como sendo o lugar do roubo e da sujeira [...] a publicidade o lugar do exercício da cidadania e da limpeza" (op. cit., p. 107). Assim,

enquanto a política é vista como o espaço da mentira, o da publicidade é encarado como o lugar da descoberta das verdades [...] Como se os valores da cidadania, democracia e ecologia se tornassem forçosamente conseqüências do ato de consumir individualmente e não mais frutos de um exercício de politização coletiva. (op. cit., p. 107)

$\mathrm{Na}$ escola, passa a existir a crença de que ser crítico é reclamar das açóes do governo, e de que a autonomia depende da capacidade de consumir discursos sem parada para reflexão. Quem diz mais e pode dizer mais exerce o poder. Essa é a percepçáo que se tem hoje da sociedade do espetáculo, imersa em tecnologias, amparada por saberes efêmeros e envolvendo sujeitos que negociam identidades. Comentando sobre a sociedade do espetáculo, Debord (1997) esclarece que, sob todas as suas formas particulares - informação ou propaganda, publicidade ou consumo direto de divertimentos -, o espetáculo constitui o modelo atual de vida dominante 
na sociedade. O espetáculo afirma a escolha já feita na produção e o consumo que decorre dessa escolha. Constrói sua unidade sobre o esfacelamento e domina o movimento de banalizaçáo dos objetos e papéis que apresenta para escolha.

Dessa forma, o indivíduo atual é resultado de um investimento político sobre a vida. No processo de constituição do indivíduo, a presença prescritiva dos códigos, interditos e mecanismos disciplinares é essencial para a compreensão da constituição do indivíduo na contemporaneidade. Nos dois últimos volumes da História da sexualidade, Foucault $(2002 ; 2006)$ vai se dedicar às formas de constituiçáo do sujeito, segundo procedimentos de uma ética apoiada na reflexão de si, acentuando as características próprias à subjetivação na atualidade. Realiza uma história da moral em função da constituição de si e não de códigos; em função do comportamento efetivo das pessoas, de sua relação consigo mesmas, que é a ética. Em uma entrevista a Rabinow e Dreyfus, Foucault (1995, p. 255) esclarece:

O que me surpreende é que na época grega as pessoas estavam preocupadas com a sua conduta moral, sua ética, suas relaçôes consigo mesmas e com os outros muito mais do que com os problemas religiosos [...] a ética não se relacionava a nenhum sistema social institucional - nem sequer a nenhum aspecto legal. [...] a sua preocupação, seu tema, era constituir um tipo de ética que fosse uma estética da existência. [...] eu me pergunto se nosso problema hoje em dia não é, de certo modo, semelhante, já que a maior parte das pessoas não acredita mais que a ética esteja fundada na religiáo, nem sejam um sistema legal para intervir em nossa vida moral, pessoal e privada. [...] Eles (os recentes movimentos de liberaçáo) necessitam de uma ética, porém não conseguem encontrar outra senão aquela fundada no dito conhecimento científico do que é o eu, do que é o desejo, do que é o inconsciente etc.

Ao falar do conteúdo ético da constituição do sujeito na Antiguidade, Foucault confronta esse sujeito com a forma de constituição do sujeito da modernidade: destituída de todo cuidado ético; há ausência de ética e de estética nas formas de subjetivação. $\mathrm{O}$ poder da norma impede a ética. Em "Uma estética da existência”, Foucault (2004c) demonstra que a ética dos gregos tratava-se de uma elaboração da vida como uma obra de arte. As formas de constituição do sujeito na era moderna propiciaram práticas que, hoje, descartam a relaçáo do indivíduo consigo mesmo, e o sujeito é o 


\section{Revista Solta a Voz, v. 19, n. 1}

resultado dos mecanismos de objetivação e de subjetivação do poder normalizador. Contudo, como se pode observar pelos discursos que circulam na mídia, quando os problemas atuais, como segurança, governo, educação, saúde etc. se apresentam, há um desejo de uma ética, mas, ao mesmo tempo, as soluçóes propostas estáo respaldadas pelo código, pela ciência, pela religiáo, e não pelo exercício de um sujeito constituindo sua própria conduta moral, com vistas a dar à sua existência a forma mais bela possível.

Pensando nesse tipo de ética, interditada há tempos pelos dispositivos disciplinares e controladores da modernidade e da pós-modernidade, pode ser relevante que haja uma reflexáo acerca das regras, normas, leis e dos códigos que são inventados para garantir o bem-estar, mas que acabam por ocupar o espaço de construção que deveria partir do próprio sujeito. Como exemplo, pode-se tomar a violência comandada por presidiários que se instaurou no Brasil, aterrorizando as famílias ditas de bem como também as ditas marginais. Diante dos acontecimentos, os comentários, vindos de várias esferas da sociedade por meio da enunciação de seus representantes, culpavam as formas de punição, o fracasso da educaçáo, o descaso do governo, a corrupção dos policiais, a desestruturação da família. Parece que a situação chega ao ponto de as pessoas apontarem tantos culpados que já não se sabe mais se há culpados. No "indiscutível fracasso" da educação, de quem é a culpa? O que todos nós, envolvidos de alguma forma nesse emaranhado de enunciados, estamos fazendo de nós mesmos? Há contradiçóes inerentes aos discursos, mas há também contradiçóes que são impostas pelo exercício de poder que, na atualidade, é sutil e se esconde atrás da idéia de que há alguém que está zelando pela vida de todos.

Gallo (2006, p. 186), ao discorrer sobre a ética na educação, recupera, em seu texto, uma preocupação de Foucault acerca do cuidado de si:

1. vivemos contemporaneamente o cuidado do outro como um governo do outro, um exercício de poder voltado para o controle, para o domínio das vontades, para uma espécie de repressão; 2 . porém, quando investigamos o mundo antigo, vemos que o cuidar de si é tomado como necessário para governar a cidade [...]; 3. assim, o cuidado (governo) de si e o cuidado (governo) do outro inscrevem-se num contexto de prática de liberdade, e não da repressão, como conhecemos hoje; 4. qual o "momento da virada"?, isto é, em que momento da história o poder passa a ser mais repressivo do que afirmativo, o cuidado de si passa a ser um exercício de disciplina, e o cuidado do outro passa a ser governamentalidade? 
Ele apresenta a resposta: "a virada é marcada pelo predomínio da moral cristá, uma moral fundada na negação de si mesmo” (Gallo, 2006 , p. 187). Essa virada abre espaço para saberes constituídos por outras práticas que levarão o indivíduo à busca por se conhecer por uma verdade vinculada à razáo, por meio de discursos advindos dos saberes científicos.

Assim, em nossa atualidade, constituídos como sujeitos de um poder normalizador, os indivíduos não percebem outras alternativas para a solução dos problemas que não sejam aquelas dadas pelos discursos autorizados e reconhecidos como verdade pelo poder-saber. Com o excesso de informaçóes e de comentários sobre os acontecimentos que são construídos, não há espaço para a reflexão, pois ainda é o código que domina e dita os comportamentos e os discursos. A ética almeja o exercício da liberdade.

Nesse sentido, me aproprio das palavras de Gallo para fechar minha reflexão dizendo que o educador precisa "adestrar-se" a si mesmo, construirse como educador, para que possa educar e preparar o aluno para "adestrarse" a si mesmo. O desafio maior para o educador do século XXI, em que parece que tudo pode ser dito por todos, é praticar uma ética como estética de sua existência como educador, que vai além do cumprimento dos planos de educação e dos projetos pedagógicos, se situando em sua própria prática cotidiana em sala de aula, na sua relação com os alunos. O cuidado de si é a possibilidade de resistência e de conquista da autonomia.

\section{REFERÊNCIAS}

BAUMAN, Z. Identidade. Rio de Janeiro: Jorge Zahar Editor, 2005.

DEBORD, G. A sociedade do espetáculo. Rio de Janeiro: Contraponto, 1997.

DELEUZE, G. Foucault. São Paulo: Brasiliense, 2005. . Conversaçóes. São Paulo: Ed. 34, 1992.

DOSSE, F. História do estruturalismo. v. 2: O canto do cisne. Bauru, SP: Edusc, 2007.

FONSECA, M. A. da. Michel Foucault e a constituição do sujeito. São Paulo: EDUC, 2003. 


\section{Revista Solta a Voz, v. 19, n. 1}

FOUCAULT, M. A verdade e as formas jurídicas. Rio de Janeiro: Nau Ed., 1996.

História da sexualidade 1: a vontade de saber. Rio de Janeiro, Ed. Graal, 2001. Graal, 2006.

. História da sexualidade 2: o uso dos prazeres. Rio de Janeiro: Ed.

. História da sexualidade 3: o cuidado de si. Rio de Janeiro: Ed. Graal, 2002.

. O cuidado com a verdade. In: MOTTA, M. B. da (Org.) Foucault: Ética, sexualidade, política. Ditos e Escritos V. Rio de Janeiro: Forense Universitária, 2004a. p. 240-251.

. O poder psiquiátrico. São Paulo: Martins Fontes, 2006.

. O retorno da moral. In: MOTTA, M. B. da (Org.) Foucault: Ética, sexualidade, política. Ditos e Escritos V. Rio de Janeiro: Forense Universitária, 2004b. p. 252-263.

. O sujeito e o poder. In: RABINOW, P. e DREYFUS, H. Michel Foucault: uma trajetória filosófica - para além do estruturalismo e da hermenêutica. Rio de Janeiro: Forense Universitária, 1995. p. 231-249.

. Uma estética da existência. In: MOTTA, M. B. da (Org.) Foucault: Ética, sexualidade, política. Ditos e Escritos V. Rio de Janeiro: Forense Universitária, 2004c. p. 288-293.

. Vigiar e punir: nascimento da prisão. Petrópolis: Vozes, 1987.

GALLO, S. Cuidar de si e cuidar do outro: implicaçóes éticas para a educação dos últimos escritos de Foucault. In: KOHAN, W. O. e GONDRA, J. Foucault 80 anos. Belo Horizonte: Autêntica, 2006. p. 71-79.

HARDT, M. e NEGRI, A. Império. Rio de Janeiro: Record, 2004.

MACHADO, R. Por uma genealogia do poder. In: FOUCAULT, M. Microfísica do poder. Rio de Janeiro: Ediçôes Graal, 2003. p. vii-xxiii.

MARTINS, M. C. E se o Outro é o professor? Reflexóes acerca do currículo e histórias de vida. In: GALLO, S. e SOUZA, R. M. Educação do preconceito: ensaios sobre poder e resistência. Campinas: Ed. Alínea, 2004. p. 103-118. 
RABINOW, P. e DREYFUS, H. Michel Foucault: uma trajetória filosófica - para além do estruturalismo e da hermenêutica. Rio de Janeiro: Forense Universitária, 1995.

SANT'ANNA, D. B. Transformaçóes do corpo: controle de si e uso dos prazeres. In: RAGO, M.; ORLANDI, L. B. L.; VEIGA-NETO, A. Imagens de Foucault e Deleuze: ressonâncias nietzschianas. Rio de Janeiro: DP\&A Ed., 2005. p. 99-110.

VEIGA-NETO, A. Foucault e a educação. Belo Horizonte: Autêntica, 2003.

Recebido em: 10 abr. 2008 Aceito: 10 jun. 2008 